OPEN ACCESS

Edited by:

Yi Zhang,

First Affiliated Hospital of Zhengzhou

University, China

Reviewed by:

Weidong Han,

People's Liberation Army General

Hospital, China

Jason Lees,

Uniformed Services University of the

Health Sciences, United States

*Correspondence:

Xue-Jun Guo pygxj@163.com

Specialty section:

This article was submitted to

Cell Death and Survival,

a section of the journal

Frontiers in Cell and Developmental

Biology

Received: 13 January 2020

Accepted: 16 April 2020

Published: 08 May 2020

Citation:

Wei $Y-H, H e Y-Z, L$ in $X-Y$, Ren $F-X$, Zhu H-B, Cheng Y, Nan Z, Liu Z-B, Yu J-Y and Guo X-J (2020) Regional

Injection of CAR-T Cells

for the Treatment of Refractory and Recurrent Diffuse Large B Cell

Lymphoma: A Case Report.

Front. Cell Dev. Biol. 8:333.

doi: 10.3389/fcell.2020.00333

\title{
Regional Injection of CAR-T Cells for the Treatment of Refractory and Recurrent Diffuse Large B Cell Lymphoma: A Case Report
}

\author{
Yan-Hui Wei', Yu-Zhuo He', Xiao-Yan Lin², Fu-Xian Ren², Hong-Bin Zhu'2, Ying Cheng', \\ Zhen $\mathrm{Nan}^{2}$, Zheng-Biao Liu' ${ }^{2}$, Jing-Ya Yu ${ }^{2}$ and Xue-Jun Guo ${ }^{2 *}$ \\ ${ }^{1}$ Department of Graduate School, Xinxiang Medical University, Henan, China, ${ }^{2}$ Puyang Oilfield General Hospital, Puyang, \\ China
}

Background: Lymphoma is a common hematological malignancy with many subtypes and considerable heterogeneity. Traditional treatments include chemotherapy, radiotherapy, and surgery. Patients with relapsed, refractory or advanced stage lymphoma have a dismal prognosis. In recent years, chimeric antigen receptors (CARs) have been recognized as powerful tools that redirect antigen-specific $\mathrm{T}$ cells independent of human lymphocyte antigen (HLA) restriction and specifically kill tumor cells. Satisfactory results with CAR-based treatments have been achieved in relapsed/refractory B cell leukemia/lymphoma. Our center explored the strategy of subcutaneous injections combined with intravenous drip to overcome certain issues.

Case Presentation: A patient with stage IV refractory and relapsed diffuse large B cell lymphoma was treated with regional and intravenous CAR-T cells. During the observation period, the temperature of the skin at the abdominal wall mass was slightly elevated, and tolerable pain in the injection area was reported. Imaging showed regional liquefactive necrosis. After the sequential administration of ibrutinib and venetoclax, the abdominal wall mass significantly decreased in size.

Conclusion: The regional injection of CAR-T cells might be safe and feasible for the treatment of regional lesions in patients with refractory and relapsed advanced lymphoma.

Keywords: chimeric antigen receptor $\mathbf{T}$ cells, diffuse large B cell lymphoma, refractory recurrence, regional injection, case report

\section{INTRODUCTION}

In June 2011, three cases of advanced chronic lymphocytic leukemia treated with chimeric antigen receptor-modified T (CAR-T) cells were reported with good curative effects (Porter et al., 2011). Since, CAR-T cell immunotherapy for relapsed and refractory lymphoma/leukaemia has developed rapidly worldwide (Maus et al., 2014; Kochenderfer et al., 2015; Zhu et al., 2016; Abramson et al., 2017; Locke et al., 2017; Neelapu et al., 2017; Schuster et al., 2017; Schmidts and Maus, 2018; Zhao et al., 2018). The conventional administration route both domestic and abroad

Abbreviations: FDG, fluoro-deoxy-glucose; $\mathrm{PD}$, progressive disease; $\mathrm{PR}$, partial remission; $\mathrm{SD}$, stable disease. 
is intravenous infusion, which is associated with various side effects,such as cytokine release syndrome, neurotoxicity, and even death (Lee et al., 2014; Neelapu et al., 2018), and this route is ineffective in some patients with local lesions. Our center administered CD19 CAR-T cells by injection into local lesions and intravenous infusion to a patient with recurrent local refractory lymphoma after several cycles of radiotherapy and chemotherapy. The results showed that local injection of the lesion was safe and well-tolerated, and the lesion became significantly smaller. These results might provide an important reference for the clinical application of CAR-T cells.

\section{CASE PRESENTATION}

A 57-year-old female patient with a weight of $70 \mathrm{~kg}$ presented at our hospital with a neck mass 5 years ago. She complained of neck discomfort in 2014 but was not prescribed medication. She presented again in May 2015 due to painless neck lymph node tumefaction without fever, for which she also did not receive medical treatment. By September 5, 2015, the bilateral lymph nodes in the neck had grown significantly, and more lymph nodes were affected. On September 8, 2015, a computed tomography (CT) scan showed tumefaction of bilateral cervical and supraclavicular lymph nodes, and the largest lymph node was $3.4 \mathrm{~cm} \times 4.3 \mathrm{~cm}$. Multiple enlarged lymph nodes were also found in the upper mediastinum, and the largest one was approximately $2.3 \mathrm{~cm} \times 1.7 \mathrm{~cm}$ and occupied the thyroid. On September 11, 2015, PET/CT imaging showed bilateral cervical and supraclavicular lymph node involvement and multiple enlarged lymph nodes in the upper mediastinum (SUVmax: 9.05). Thyroid cancer with bilateral cervical lymph node metastasis or lymphoma was suspected, and cervical lymph node biopsy was performed. The pathological findings suggested $\mathrm{T}$ cell/histiocyte-rich large $\mathrm{B}$ cell lymphoma (Figure 1). The detailed immunohistochemical findings were as follows: CD20 (2+), PAX-5 (2+), ALK (-), BCL-6 (scattered weak+), CD10 (-),

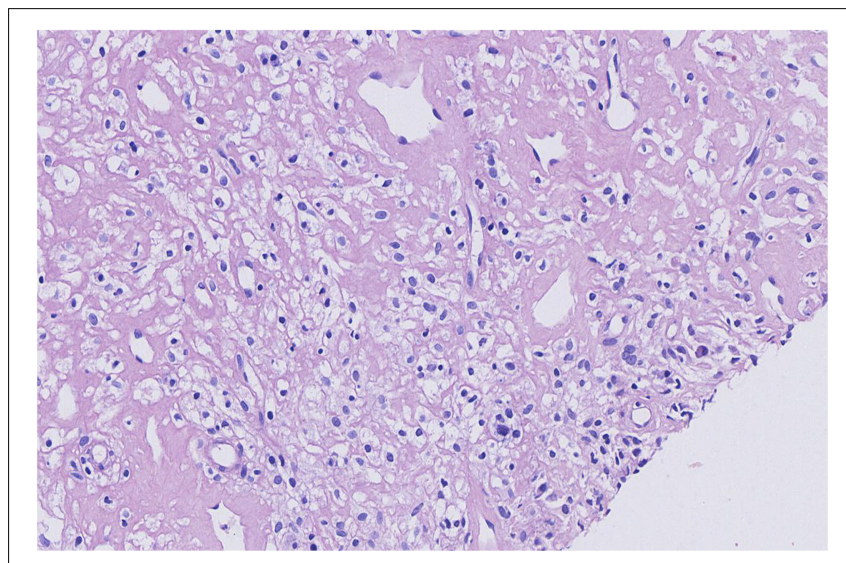

FIGURE 1 | Microscopic findings for the biopsied specimen before the chemotherapy regimen was chosen. T cell/histiocyte-rich large B cell lymphoma.
CD2 (-), CD21 (-), CD3 (-), CD30 (1+), CD4 (-), CD5 ( \pm , CD56 ( \pm ), Ki67 (+60\%), PD-1 (-), TIA1 (-), CD15 (-), LCA $(3+)$, S-100 (-), CD68 ( \pm ), CD1a (-), and CD35 (-). The biopsy was negative for Epstein-Barr virus (EBV)-encoded RNA (EBER). The specific treatments are shown in Table 1.

Re-examination by PET/CT showed multiple small and swollen lymph nodes in the right lateral iliac vessels and the right groin area that were partially fused into a clump, with a size of approximately $71 \mathrm{~mm} \times 72 \mathrm{~mm} \times 98 \mathrm{~mm}$. The boundary with the adjacent abdominal oblique muscle and skin was unclear, the adjacent abdominal oblique muscle was thickened, the surrounding fat was turbid, and fluoro-deoxy glucose (FDG) metabolism was increased, with a SUVmax of 24.48. The right abdominal oblique muscle was invaded by lymphoma (Figure 2). Based on the above analysis, repeated systemic chemotherapy and local radiotherapy were applied, but the tumor still recurred in the local superficial area. This recurrence may be related to changes in the local anatomy of the patient after repeated treatment, and as a result, the drug could not reach an effective concentration locally. However, related chemotherapy drugs have no indication for local subcutaneous injection; therefore, CD19 CAR-T cell therapy was considered. On June 6, 2019, the baseline levels of cytokines (including IL-2, IL-4, IL-6, IL10 , TNF- $\alpha$, and IFN- $\gamma$ ) were normal. An FC preconditioning regimen (fludarabine $30 \mathrm{mg} \mathrm{d} 1-3$ and cyclophosphamide $400 \mathrm{mg}$ $\mathrm{d} 1+600 \mathrm{mg} \mathrm{d} 2$ ) was administered on the same day, June 11, 2019, CD19 CAR-T cell treatment was started. Due to the local "barrier effect" of the lesion, we considered the possibility that the applied cells may not be able to affect the local area after intravenous infusion. Therefore, an approach of intravenous infusion combined with local injection was undertaken. Our center uses second-generation CD19 CAR-T cells generated by genetic engineering technology, in which the CAR domain that specifically recognizes tumor cells is transferred to activated $\mathrm{T}$ cells by lentivirus. The extracellular antigen-binding region is a single-chain variable region of a CD19-specific mouse antigen. With regard to the selection of intracellular costimulatory domains, related studies indicate that 4-1BB has better efficacy than CD28 (Zhi et al., 2018); therefore, our center utilizes the $4-1 \mathrm{BB}$ costimulatory domain. After the CAR-T cell therapy is constructed, it undergoes in vitro amplification and then is infused into patients. At present, the number of cells infused intravenously for this treatment at home and abroad is 1$10 \times 10^{6} / \mathrm{kg}$ (Kochenderfer et al., 2015; Neelapu et al., 2017; Schuster et al., 2017). The total number of cells administered to this patient was $5.78 \times 10^{8}$, and the following results were recorded: cell viability: $98.51 \%$ (trypan blue staining); cell marker detection: $\mathrm{CD} 3$ + CD 4 + + CD3 + CD8 + > 95\%; CAR19positive rate: $63.65 \%$; cell death activity: $48 \mathrm{~h}, \mathrm{~F}: \mathrm{T}=1: 1$, Raji: CD19 ratio $<20 \%$. The cells $\left(5.48 \times 10^{8}\right)$ were suspended in $100 \mathrm{ml}$ of physiological saline for intravenous infusion, which proceeded normally, and the remaining $3.0 \times 10^{7}$ cells were suspended in $10 \mathrm{ml}$ of physiological saline for local treatment. According to the requirements for conventional surgery, under ultrasound guidance, we first selected an injection point in each of the four directions around the right lower abdominal wall mass. We injected $2 \mathrm{ml}$ along each edge of the mass 
TABLE 1 | Treatment process and results.

\begin{tabular}{|c|c|c|}
\hline Date & Treatment & Response \\
\hline 2015.10.16-2016.01.11 & $\mathrm{R}-\mathrm{CHOP} / 4$ cycles & PD \\
\hline 2016.01.16-2016.04.10 & R-GDPI/4 cycles & $\mathrm{SD}$ \\
\hline 2016.04.15-2016.06.13 & Etoposide + doxorubicin liposome + thalidomide/2 cycles & PD \\
\hline 2016.09.12-2016.10.07 & Regional radiotherapy (20 Gy/20 times/25 days) & PR \\
\hline \multicolumn{3}{|c|}{$\begin{array}{l}\text { The patient's condition was stable during this period. On February } 2017 \text {, a right abdominal wall mass was found, and a puncture biopsy was performed. Patholog } \\
\text { revealed a T cell/histiocyte-rich large B cell lymphoma. On June 08, 2017, the abdominal wall mass was surgically resected because of ulceration. The } \\
\text { postoperative pathological findings indicated lymphoma. }\end{array}$} \\
\hline 2017.07.17-2017.12.25 & MabThera + pemetrexed + dexamethasone/8 cycles & PR \\
\hline \multicolumn{3}{|c|}{$\begin{array}{l}\text { 2017.12.26-2018.06.10 The patient's condition was stable, and clinical observation was performed at home. A mass on the right lower abdominal wall was again } \\
\text { found on June } 14,2018 \text {. }\end{array}$} \\
\hline 2018.06.28-2018.11.06 & Pemetrexed + melphalan/6 cycles & 2 cycles, PR4 cycles, PR6 cycles, PD \\
\hline 2018.11.17-2019.01.15 & Cisplatin + isocyclophosphamide + etoposide + dexamethasone/2 cycles & $\mathrm{PD}$ \\
\hline \multicolumn{3}{|c|}{$\begin{array}{l}\text { 2019.01.14 Ultrasound examination: Soft subcutaneous swelling and uneven echo at the incision from the right lower abdomen to the right groin area was } \\
\text { observed, and an irregular hypoechoic range of approximately } 35 \mathrm{~mm} \times 32 \mathrm{~mm} \times 22 \mathrm{~mm} \text { was visible at the lower edge of the incision. The boundary was unclea } \\
\text { and the local blood flow signal was increased. We considered the chemotherapy to be ineffective. }\end{array}$} \\
\hline 2019.01.28-2019.02.26 & Regional radiotherapy (40 Gy/20 times/29 days) & $\mathrm{PR}$ \\
\hline 2019.02.27-2019.04.14 & Lenalidomide & PD \\
\hline 2019.04.15-2019.04.20 & Lenalidomide + MabThera and local radiotherapy (10 Gy/5 times/5 days) & PD \\
\hline
\end{tabular}

and then injected $2 \mathrm{ml}$ in the center of the mass (Figure 3). The patient experienced no obvious discomfort except local swelling and pain. After 7 days of evaluation, the patient had no discomfort. The patient's body temperature was $36.5^{\circ}$, the local skin temperature was $37.2^{\circ}$, and a scab appeared on the original skin mass with little exudation and was disinfected and covered with sterile dressings. The levels of the cytokines IL-6 and IL-10 in the blood appeared to slightly increase, 10.49 and $8.47 \mathrm{pg} / \mathrm{ml}$, respectively, but the other factors were normal. At the evaluation on day 14, the patient complained of nocturnal pain in the mass, had a body temperature of $36.6^{\circ}$ and a local skin temperature of $38.0^{\circ}$, and the levels of cytokines IL-6 and IL-10 had increased again (24.92 and 8.66 $\mathrm{pg} / \mathrm{ml}$ ), but the other factors were normal. At 16 days after the injection, ultrasonography detected a blurred mass of fused flakes ( $53 \mathrm{~mm} \times 15 \mathrm{~mm}$ ) with a slightly enhanced heterogeneous internal echo and abundant internal and surrounding blood flow in the right lumbar region and subcutaneous area of the right inferior abdomen. A cytological examination was suggested, but the patient requested to be discharged. Her out-patient treatment regimen was ibrutinib $400 \mathrm{mg} / \mathrm{d}+$ venetoclax $200 \mathrm{mg} / \mathrm{d}$, and she reported a stable general condition. PET/CT imaging in August 2019 showed that the muscular tissue in the right anteroinferior abdominal wall had become thicker, with a slightly lowdensity shadow, unclear boundary and increased radioactivity uptake. The maximal cross-sectional area of the enhanced uptake shadow was $34 \mathrm{~mm} \times 11 \mathrm{~mm}$ (SUVmax: 9.5), indicating increased tissue metabolism and a suspected malignant lesion. A regional flocculent, flaky, radiopaque shadow was observed in the subcutaneous areas of the right anteroinferior abdominal wall and right inguinal region (CT value: $27 \mathrm{Hu}$ ) with unclear boundaries. The radioactivity uptake was slightly increased

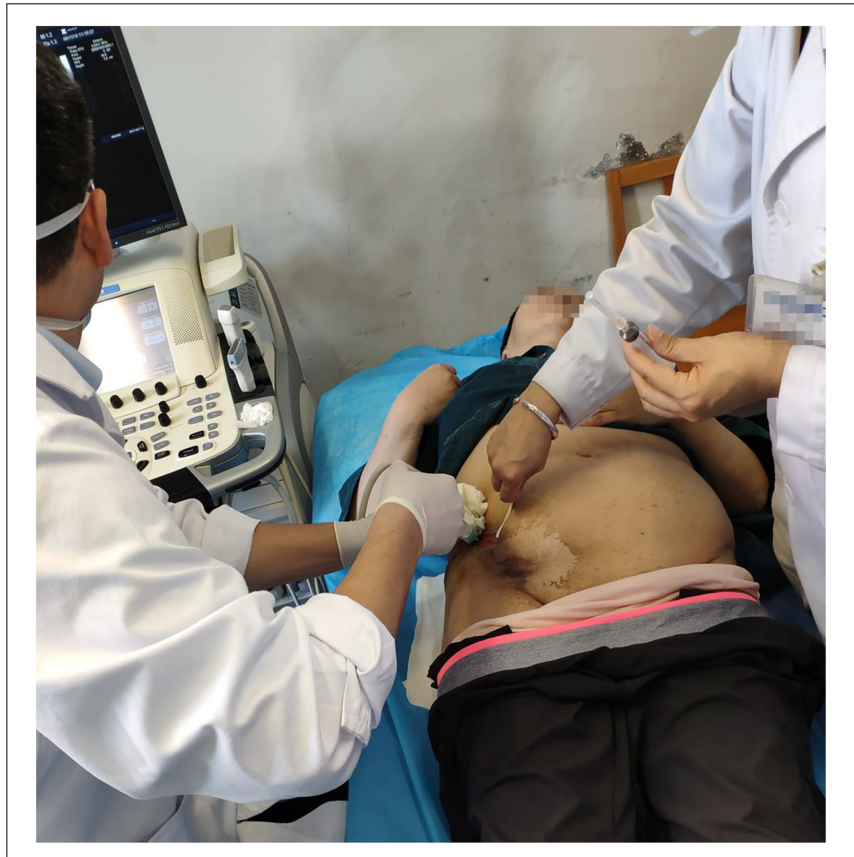

FIGURE 3 | Picture of the local injection site.

(maximum SUV: 2.0), suggesting a higher level of metabolism. There was a soft tissue nodule beside the right lateral iliac artery with a maximum cross-sectional area of $20 \mathrm{~mm} \times 8 \mathrm{~mm}$ (CT value: $54 \mathrm{Hu}$ ), slightly enhanced radioactivity uptake (SUVmax: 6.3), and increased metabolism, suggesting malignant lymph node lesions (Figure 4). 


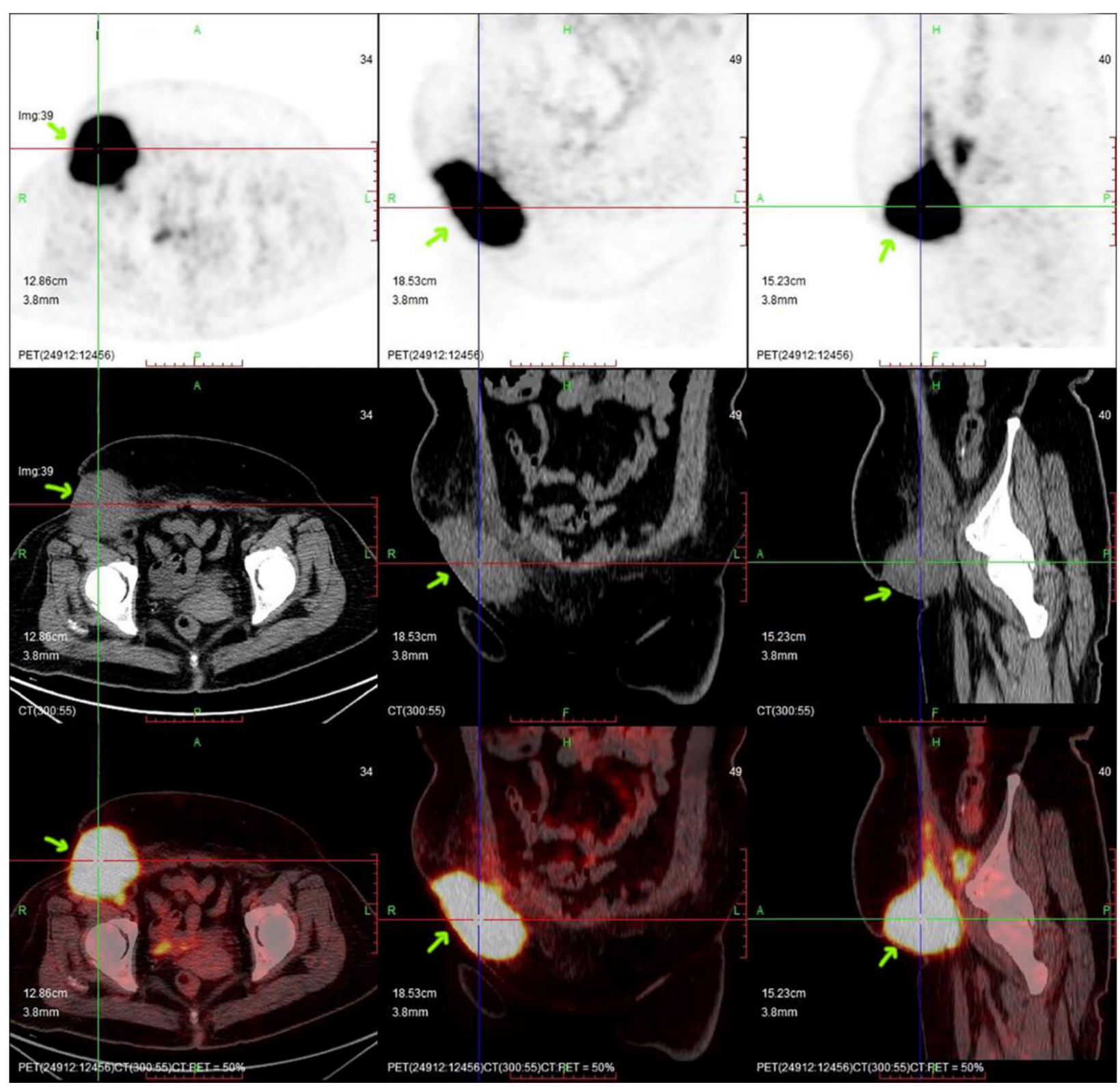

FIGURE 2 | PET/CT imaging before CAR-T cell infusion. The position indicated by the arrow is the location of the lesion, which had a volume of $\sim 71 \mathrm{~mm} \times 72 \mathrm{~mm} \times 98 \mathrm{~mm}$ (arrow).

\section{DISCUSSION AND CONCLUSION}

T lymphocytes play a key role in the cell-mediated immune response, and the body mainly relies on cytotoxic $\mathrm{T}$ lymphocytes (CTLs) to kill tumor cells. However, CTL function depends on antigen processing and presentation by MHC molecules (Reyburn et al., 1997), and these events are the main processes of tumor cell escape from immunosurveillance. CAR-T cells bypass the antigen presentation stage and MHC restriction and specifically kill tumor cells. There have been remarkable achievements in the treatment of relapsed/refractory B cell leukemia/lymphoma (Maus et al., 2014; Abramson et al., 2017;
Kochenderfer et al., 2017; Locke et al., 2017). For our patient, the tumor recurred repeatedly under the local skin. Several imaging examinations indicated only regional invasion. The response to conventional radiotherapy and chemotherapy was poor, considering that the local anatomy of the patient may change after repeated treatment. The conventional methods of drug administration cannot achieve the effective concentration required for local treatment. Therefore, based on the treatment effect of the patient, it may be difficult to achieve the therapeutic effect only by the method of intravenous injection, so intravenous infusion combined with regional injection is used for treatment. During this process, the patient experiences local pain and an 


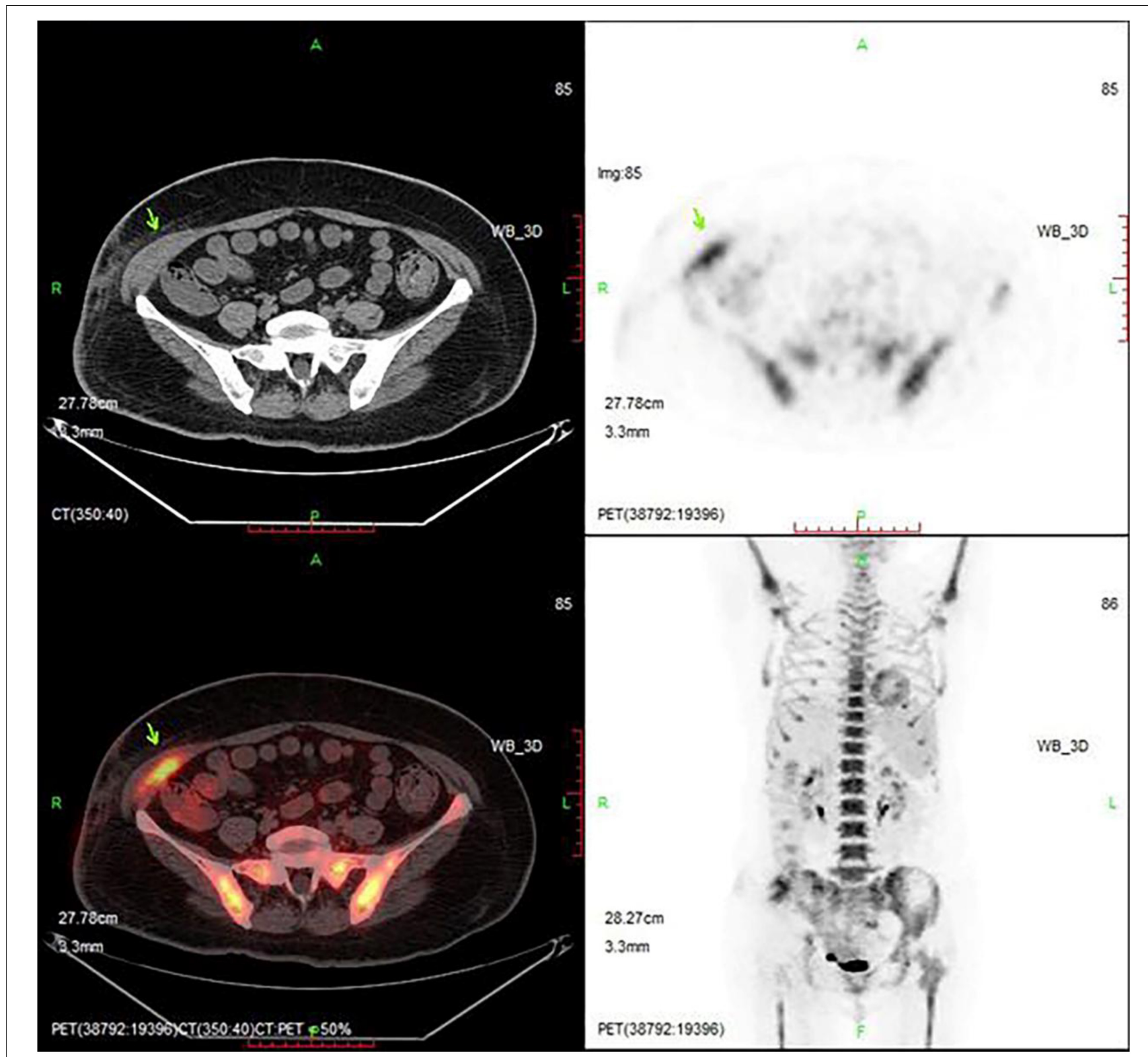

FIGURE 4 | PET/CT imaging after CAR-T cell infusion. The lesion is significantly smaller than before. The position indicated by the arrow is the location of the lesion.

increase in skin temperature, which can be tolerated. Because of poor patient compliance, regional efficacy and cytological evaluations were not conducted in a timely manner. Relevant studies both at home and abroad suggest that after the completion of cell therapy, ibrutinib and venetoclax should be sequentially orally administered to the patient as part of the overall treatment regimen (Fraietta et al., 2016). Sixty days after the CAR-T cell injection, imaging examinations revealed that the mass in the original injection area had become significantly smaller. The patient developed local swelling, pain and fever during cell therapy, and the levels of the cytokines IL- 6 and IL-10 increased to varying degrees. In addition, the local mass was clearly smaller, suggesting that the combined CD19 CAR-T cell strategy demonstrated a good response to the mass, and the side effects can be tolerated. However, we cannot completely exclude the synergistic effect of ibrutinib and venetoclax. Ibrutinib has been reported to have a synergistic effect with CAR-T cells (Fraietta et al., 2016; Long et al., 2017). Further analysis suggested that the regional injection and intravenous infusion of CAR-T cells for the treatment of refractory and relapsed advanced lymphoma did not cause serious local or systemic adverse reactions, indicating that local treatment is safer. In terms of efficacy, the results of this research are preliminary. Because of the use of ibrutinib, further research is needed to ascertain the specific efficacy of the CAR-T cells, and the specific injection dose, injection techniques, injection timin,g and combined medications will be the next 
focuses of our research. This treatment method provides a new option for the clinical application of cellular immunotherapy as well as a reference for the treatment of other solid tumors.

\section{DATA AVAILABILITY STATEMENT}

All datasets generated for this study are included in the article/supplementary material.

\section{ETHICS STATEMENT}

This study was approved by the Ethics Committee of Xinxiang Medical College affiliated with Puyang Oilfield General Hospital (review number: 2019-04-0006-E01) and was performed with the consent of the patient and family members.

\section{REFERENCES}

Abramson, J. S., Mcgree, B., Noyes, S., Plummer, S., Wong, C., Chen, Y.-B., et al. (2017). Anti-CD19 car T cells in CNS diffuse large-B-cell lymphoma. N. Engl. J. Med. 377, 783-784. doi: 10.1056/NEJMc1704610

Fraietta, J. A., Beckwith, K. A., Patel, P. R., Ruella, M., Zheng, Z., Barrett, D. M., et al. (2016). Ibrutinib enhances chimeric antigen receptor T-cell engraftment and efficacy in leukemia. Blood 127, 1117-1127. doi: 10.1182/blood-2015-11679134

Kochenderfer, J. N., Dudley, M. E., Kassim, S. H., Somerville, R. P. T., Carpenter, R. O., Stetler-Stevenson, M., et al. (2015). Chemotherapy-refractory diffuse large B-cell lymphoma and indolent B-cell malignancies can be effectively treated with autologous $\mathrm{T}$ cells expressing an anti-CD19 chimeric antigen receptor. J. Clin. Oncol. 33, 540-549. doi: 10.1200/jco.2014.56.2025

Kochenderfer, J. N., Somerville, R. P. T., Lu, T., Yang, J. C., Sherry, R. M., Feldman, S. A., et al. (2017). Long-duration complete remissions of diffuse large B-cell lymphoma after anti-CD19 chimeric antigen receptor therapy. Mol. Ther. 25, 2245-2253. doi: 10.1016/j.ymthe.2017.07.004

Lee, D. W., Gardner, R., Porter, D. L., Louis, C. U., Ahmed, N., Jensen, M., et al. (2014). Current concepts in the diagnosis and management of cytokine release syndrome. Blood 124, 188-195. doi: 10.1182/blood-2014-05-552729

Locke, F. L., Neelapu, S. S., Bartlett, N. L., Siddiqi, T., Chavez, J. C., Hosing, C. M., et al. (2017). Phase 1 results of ZUMA-1: a multicenter study of KTE-C19 antiCD19 CAR T cell therapy in refractory aggressive lymphoma. Mol. Ther. 25, 285-295. doi: 10.1016/j.ymthe.2016.10.02

Long, M., Beckwith, K., Do, P., Mundy, B. L., Gordon, A., Lehman, A. M., et al. (2017). Ibrutinib treatment improves $\mathrm{T}$ cell number and function in CLL patients. J. Clin. Invest. 127, 3052-3064. doi: 10.1172/JCI89756

Maus, M. V., Grupp, S. A., Porter, D. L., and June, C. H. (2014). Antibody-modified T cells: CARs take the front seat for hematologic malignancies. Blood 123, 2625-2635. doi: 10.1182/blood-2013-11-492231

Neelapu, S. S., Locke, F. L., Bartlett, N. L., Lekakis, L. J., Miklos, D. B., Jacobson, C. A., et al. (2017). Axicabtagene ciloleucel CAR T-cell therapy in refractory large B-cell lymphoma. N. Engl. J. Med. 377, 2531-2544. doi: 10.1056/ NEJMoa1707447

Neelapu, S. S., Tummala, S., Kebriaei, P., Wierda, W., Gutierrez, C., Locke, F. L., et al. (2018). Chimeric antigen receptor T-cell therapy - assessment

\section{AUTHOR CONTRIBUTIONS}

Y-HW participated in the entire process of research, data collection, operation log recording, and wrote the first draft of the manuscript. Y-ZH analyzed and evaluated the treatment and curative effects. X-YL supervised the experimental process and standardized the technical operation. X-JG guided the entire process in terms of theory and practice and revised the manuscript. All other authors revised the manuscript.

\section{ACKNOWLEDGMENTS}

We would like to thank the technical team of Dr. Dan Wei from Hualong Biological Company for the chimeric antigen receptor $\mathrm{T}$ cells, and we are also thankful for the follow-up technical guidance of the Henan Tailijie Biotech Co., Ltd.

and management of toxicities. Nat. Rev. Clin. Oncol. 15, 47-62. doi: 10.1038/ nrclinonc. 2017.148

Porter, D. L., Levine, B. L., Michael, K., Bagg, A., and June, C. H. (2011). Chimeric antigen receptor-modified T cells in chronic lymphoid leukemia. N. Engl. J. Med. 365, 725-733. doi: 10.1056/nejmoa1 103849

Reyburn, H. T., Mandelboim, O., Valés-Gómez, M., Davis, D. M., Pazmany, L., and Strominger, J. L. (1997). The class I MHC homologue of human cytomegalovirus inhibits attack by natural killer cells. Nature 386, 514-517. doi: $10.1038 / 386514 \mathrm{a} 0$

Schmidts, A., and Maus, M. V. (2018). Making CAR T cells a solid option for solid tumors. Front. Immunol. 9:2593. doi: 10.3389/fimmu.2018.02593

Schuster, S. J., Svoboda, J., Chong, E. A., Nasta, S. D., Mato, A. R., Anak, O., et al. (2017). Chimeric antigen receptor T cells in refractory B-Cell lymphomas. N. Engl. J. Med. 377, 2545-2554. doi: 10.1056/NEJMoa1708566

Zhao, Z., Chen, Y., Francisco, N. M., Zhang, Y., and Wu, M. (2018). The application of CAR-T cell therapy in hematological malignancies: advantages and challenges. Acta Pharm. Sin. B 8, 539-551. doi: 10.1016/j.apsb.2018.03.001

Zhi, C., Runhong, W., Qiuling, M., Lin, S., Feng, H., Zixiao, S., et al. (2018). In Vivo Expansion and antitumor activity of coinfused CD28- and 4-1BB-engineered CAR-T cells in patients with B cell leukemia. J. Mol. Ther. 26, 976-985. doi: 10.1016/j.ymthe.2018.01.022

Zhu, Y., Tan, Y., Ou, R., Zhong, Q., Zheng, L., Du, Y., et al. (2016). Anti-CD19 chimeric antigen receptor-modified T cells for B-cell malignancies: a systematic review of efficacy and safety in clinical trials. Eur. J. Haematol. 96, 389-396. doi: 10.1111/ejh.12602

Conflict of Interest: The authors declare that the research was conducted in the absence of any commercial or financial relationships that could be construed as a potential conflict of interest.

Copyright (c) 2020 Wei, He, Lin, Ren, Zhu, Cheng, Nan, Liu, Yu and Guo. This is an open-access article distributed under the terms of the Creative Commons Attribution License (CC BY). The use, distribution or reproduction in other forums is permitted, provided the original author(s) and the copyright owner(s) are credited and that the original publication in this journal is cited, in accordance with accepted academic practice. No use, distribution or reproduction is permitted which does not comply with these terms. 